\title{
Development of Functional Lassi (Stirred Indian Yoghurt) Supplemented with Beetroot (Beta vulgaris) Juice
}

\author{
Manvesh Kumar Sihag,', Karuna Meghwal and Ankit Goyal \\ Dairy Chemistry Department, Mansinhbhai Institute of Dairy \& Food Technology (MIDFT), Mehsana-384002, Gujarat, \\ India
}

*Corresponding author: manveshsihag@gmail.com

Received: 25-06-2019

Revised: $18-10-2019$

Accepted: 23-11-2019

\begin{abstract}
Beetroot, a very nutritious vegetable, used for human consumption in raw and cooked form is also a potential source of saponins, betacyanines, betanin and polyphenols. Due to presence of betalains, the natural color pigments, beetroot is also used in food industry as source of natural color in various food products. Besides this, beetroot is also having therapeutic properties such as anti-oxidative, anti-inflammatory, hepatoprotective and anti-mutagenic properties. Therefore, a functional lassi (stirred Indian yoghurt) supplemented with beetroot juice was developed in the present study. Beetroot with red bulb was procured from local market of mehsana, washed, peeled and shredded before subjecting it to blanching and roasting treatments. Based on sensory evaluation, the lassi supplemented with blanched juice got significantly higher $(\mathrm{p}<0.05)$ scores than the roasted one. Further, the physicochemical and anti-oxidative properties of the developed product were also evaluated and compared with control.
\end{abstract}

Keywords: Beetroot, human consumption, lassi, yoghurt, juice

Beetroot (Beta vulgaris), belonging to Chenopodiaceae family, is a very nutritious vegetable found in a variety of bulb colors from yellow to red. Beetroot with red colored bulb is frequently used for human consumption in raw and cooked form. It contains no fat, very few calories and is a great source of folate, fiber and antioxidants particularly carotenoids and flavonoids. Beetroot is rich in bioactive components such as carotenoids (Dias et al. 2009), glycine betaine, (de Zwart et al.2003), saponins (Atamanova et al.2005), betacyanines (Patkai et al. 1997), betanin, polyphenols and flavonoids (Vali et al. 2007). Beetroot ingestion has been positively associated with cancer prevention also (Kapadia et al. 1996). Beetroot juice contains a high level of biologically accessible antioxidants and polyphenolsas well as many other essential micronutrients such as potassium, magnesium, folic acid, iron, zinc, calcium, phosphorus, sodium, niacin, biotin, pyridoxine and soluble fibre. Color and appearance areone of the most important parameters for consumer preference Wootton-Beard et al. (2011) has reported a very high total antioxidant capacity $(697.9 \pm 1.61 \mathrm{~mol} / 70 \mathrm{~mL})$ and total polyphenol content $(68.4 \pm 0.3 \mathrm{mgGAE} / 70 \mathrm{~mL})$ in beetroot shot and acceptance of any food product. Since the last decade, the consumers have changed their preference from artificial colors to the natural ones. Betalainsare water-soluble plant pigments which are naturally present in beetroot juice abundantly. In food industry, betalains are widely used as food colorants owing to its antioxidant, anti-inflammatory, hepatoprotective and anti-mutagenic properties (Georgiev, et al. 2013). Lassi (Stirred Indian yoghurt) is a popular fermented milk beverage consumed by all age groups. The 
objective of the present study was to develop value-added lassi supplemented with beetroot juice along with its physiochemical characterization and organoleptic evaluation.

\section{METHODOLOGY}

Beetroot with red bulb was purchased from local market, Mehsana, Gujarat. Beetroots were washed thoroughly with tap water before further processing. The methodology of the technical plan for the study isas mentioned below.

\section{Optimization of processing conditions of beetroot (Blanched \& Roasted)}

The beetroot used in the study was peeled and shredded into thin slices before subjecting to blanching and roasting treatments to destroy the pathogenic microorganisms and deactivate the enzymes responsible for browning and spoilage.

Blanching was performed in two ways:

1. Blanching using microwave heating with 2450MHz for 1 minute.

2. Blanching with hot water at $90^{\circ} \mathrm{C}$ for 5 minutes.

Blanched shreds were used for the juice extraction by simple juice extractor. Extracted juice was further supplemented in lassi at the rate of $1 \%, 3 \%, 5 \%$ and $7 \%$ level in order to evaluate the sensory acceptability.

Similarly, for roasting, the shreds were dry heated in a roasting pan at approximately $80-90^{\circ} \mathrm{C}$ for $2-3 \mathrm{~min}$. The roasted shreds were directly incorporated into the lassi at the levels mentioned above.

\section{Optimization of process protocol for lassi preparation}

To prepare dahi (curd), mixed milk was standardized to $1.5 \%(\mathrm{w} / \mathrm{w})$ fat content with skimmed milk powder followed by homogenization and pasteurization $\left(74^{\circ} \mathrm{C} / 15 \mathrm{~s}\right)$. Thereafter, milk was warmed to $45^{\circ} \mathrm{C}$ followed by subsequent addition of DVS culture $(1.6 \%)$ and incubation period of $6-7 \mathrm{~h}$ at $42^{\circ} \mathrm{C}$ temperature. The lassi was prepared by blending it with water. For optimization of level of water, five different combinations of curd to water viz. 2:1, 3:2, 1:1, 3:4 and 1:2 were prepared. Based on the viscosity, 3:2 (curd: water) level was selected for the fortification of beetroot juice. The level of beetroot shreds/juice to be supplemented in lassi was selected on the basis of sensory scores using a 9-point hedonic scale. The sensory parameters selected for sensory evaluation included color and appearance, consistency, taste \& flavor and overall acceptability.

3. Determination of compositional and physicochemical parameters such as total fats, protein, carbohydrates, ash content, total solids, acidity, and viscosity.

4. Microbial analysis.

5. Determination of antioxidant activity in terms of $\%$ radical scavenging activity by 1,1 -diphenyl2-picrylhydrazyl (DPPH) method.

6. Shelf-life/storage study for 15 days stored at refrigerated temperature $\left(4-7^{\circ} \mathrm{C}\right)$

\section{RESULTS}

Based on the sensory scores, the formulation in which roasted beetroot shreds were supplemented in lassi, got significantly $(\mathrm{p}<0.05)$ lower sensory scores in terms of mouthfeel, consistency and taste when compared with lassi samples fortified with blanched beetroot shreds. Another problem with roasted beetroot shreds supplemented lassi samples was the objectional/lingering after-taste as observed by the sensory panel. However, when lassi samples supplemented with blanched shreds were compared with beetroot juice fortified samples, again, substantially lower sensory scores were obtained for former samples. In case of shreds added samples, lower acceptability scores could beattributed to the fact that the shreds were not able to disperse uniformly throughout the sample and settled down to the bottom of the container when the sample left undisturbed for some time. The smoothness of lassi as a ready-to-serve beverage was also hampered due to the presence of beetroot shreds. Therefore, on the basis of sensory scores and overall acceptability, lassi 
Development of Functional Lassi (Stirred Indian Yoghurt) Supplemented with Beetroot (Beta vulgaris) Juice

Table 1: Sensory scores of $3 \%$ beetroot juice fortified lassi at $0^{\text {th }}$ and $15^{\text {th }}$ day of storage

\begin{tabular}{|c|c|c|c|c|c|c|c|c|}
\hline \multirow{3}{*}{ Lassi sample } & \multicolumn{2}{|c|}{ Colour and appearance } & \multicolumn{2}{|c|}{ Consistency } & \multicolumn{2}{|c|}{ Taste and flavour } & \multicolumn{2}{|c|}{ Acidity } \\
\hline & \multicolumn{8}{|c|}{ Days of storage } \\
\hline & 0 & 15 & 0 & 15 & 0 & 15 & 0 & 15 \\
\hline Control & $7.46 \pm 1.98^{\mathrm{a}}$ & $7.29 \pm 2.19^{a}$ & $7.99 \pm 0.82^{\mathrm{a}}$ & $7.11 \pm 1.02^{\mathrm{a}}$ & $7.50 \pm 1.15^{\mathrm{a}}$ & $7.01 \pm 1.21^{\mathrm{a}}$ & $7.59 \pm 2.12^{a}$ & $6.99 \pm 1.60^{\mathrm{a}}$ \\
\hline $\begin{array}{l}3 \% \text { beetroot } \\
\text { fortified lassi }\end{array}$ & $7.36 \pm 0.74^{\mathrm{a}}$ & $7.82 \pm 1.11^{\mathrm{a}}$ & $8.01 \pm 0.25^{\mathrm{a}}$ & $7.58 \pm 0.84^{\mathrm{a}}$ & $8.22 \pm 0.79^{a}$ & $7.82 \pm 1.93^{a}$ & $7.84 \pm 0.48^{\mathrm{a}}$ & $7.00 \pm 1.21^{\mathrm{a}}$ \\
\hline
\end{tabular}

Values are mean \pm S.D. $(n=9)$. Values with different superscripts letters within a column indicate significant difference from each other $(p<0.05)$.

fortified with beetroot juice was selected for further study and final product optimization.

When lassi was fortified with beetroot juice at different levels (1\%, 3\%, 5\% and 7\%) and evaluated for sensory scores, $3 \%$ fortified sample showed significantly $(p<0.05)$ higher scores for colour and appearance than that of rest of the fortified samples as well as control. Therefore, $3 \%$ fortified lassi sample in which juice was extracted from hot water blanched $\left(90^{\circ} \mathrm{C}\right.$ for $\left.5 \mathrm{~min}\right)$, was selected for further physicochemical and functional properties. Data showed that the final fortified product ( $3 \%$ juice fortified) contained $12.80 \%$ total solids, $1.5 \%$ total fats, $11.30 \%$ solid-not-fats (SNF), $0.36 \%$ titratable acidity and16.9 $c p$ viscosity. There was no significant change $(p>0.05)$ in studied physico-chemical parameters except titratable acidity, which significantly $(\mathrm{p}<0.05)$ during storage but remained in limit with acceptable sensory scores (sourness) (Table 1).

Overall, sensory evaluation indicated that the product was acceptable up to 15 days when stored at $4-7^{\circ} \mathrm{C}$ storage temperature. Results of antioxidant activity suggested that $3 \%$ beetroot juice fortified lassi showed significantly $(\mathrm{p}<0.05)$ higher \% radical scavenging activity [38.92 \pm 3.18 Gallic acid equivalent (GAE)] than that of control $(14.26 \pm 2.12$ GAE) at zero day. There was a slight decrease in antioxidant activity throughout the storage but the change was non-significant $(\mathrm{p}>0.05)$. Overall, it can be concluded that beetroot juice fortified (at 3\% level) lassi was superior to control in terms of sensory acceptability as well as antioxidant activity throughout the storage period of 15 days when stored at low temperature.

\section{CONCLUSION}

It can be concluded that the developed lassi supplemented with beetroot juice proved to be a highly nutritious fermented dairy product, rich in antioxidants, phytonutrients and anti-inflammatory components. Moreover, it contains natural color and pigments and hence no artificial color and flavor was used. The product is rich in minerals and possesses better sensory scores in terms of colour, mouthfeel, taste \& flavour and overall acceptability than that of control.

\section{REFERENCES}

Atamanova, S.A., Brezhneva, T.A., Slivkin, A.I., Nikolaevskii, V. A., Selemenev, V.F., and Mironenko, N.V. 2005. Isolation of saponins from table beetroot and primary evaluation of their pharmacological activity. Pharm. Chem. J., 39(12): 650652.

Brand-Williams, W., Cuvelier, M. and Berset, C. 1925. Antioxidant activity determined using stable radical, 1, 1-diphenyl-2-picrylhydrazyl (DPPH). Lebens-Wiss-Technol., 28: 25.

De Zwart, F.J., Slow, S., Payne, R.J., Lever, M., George, P.M., Gerrard, J.A. and Chambers, S.T. 2003. Glycine betaine and glycine betaine analogues in common foods. Food Chem., 83(2): 197-204.

Dias, M.G., Camões, M.F.G. and Oliveira, L. 2009. Carotenoids in traditional Portuguese fruits and vegetables. Food Chem., 113(3): 808-815.

Georgiev, V.G., Bley, T. and Pavlov, A.I. 2013. Bioreactors for the cultivation of red beet hairy roots. In Red beet biotechnology (pp. 251-281).Springer, Boston, MA.

Jastrebova, J., Witthöft, C., Grahn, A., Svensson, U. and Jägerstad, M. 2003. HPLC determination of folates in raw and processed beetroots. Food Chem., 80(4): 579-588. 
Kapadia, G.J., Tokuda, H., Konoshima, T. and Nishino, H. 1996. Chemoprevention of lung and skin cancer by Beta vulgaris (beet) root extract. Cancer Letters, 100(1-2): 211-214.

Patkai, G.Y., Barta, J. and Varsanyi, I. 1997. Decomposition of anticarcinogen factors of the beetroot during juice and nectar production. Cancer Letters, 1(114): 105-106.
Váli, L., Stefanovits-Bányai, É., Szentmihályi, K., Fébel, H., Sárdi, É., Lugasi, A. and Blázovics, A. 2007. Liverprotecting effects of table beet (Beta vulgaris var. rubra) during ischemia-reperfusion. Nutrition, 23(2): 172-178.

Wootton-Beard, P.C. and Ryan, L. 2011. A beetroot juice shot is a significant and convenient source of bioaccessible antioxidants. J Funct. Foods, 3(4): 329-334. 